Reprod. Nutr. Dévelop., 1987, 27 (1 B), 243-245.

\title{
Teneur et composition des lipides des bactéries du rumen libres et adhérant aux particules chez la vache : influence des régimes riches en matières grasses non protégées
}

\author{
Françoise LEGAY-CARMIER, D. BAUCHART, M. DOREAU $\left(^{*}\right)$
}

Laboratoire d'Etude du Métabolisme Energétique,

(*) Laboratoire de la Lactation,

I.N.R.A. Theix, 63122 Ceyrat, France.

Summary. Average lipid composition of solid-adherent bacteria (SAB) differed from that of liquid-associated bacteria $(L A B)$ in the rumen by a phospholipid ( $P L)$ free fatty acid (FFA) ratio which amounted to 0.78 and 2.71 respectively $(P<0.05)$ in dairy cows fed a hay and concentrate $(50 / 50)$ diet. When the diet was supplemented with rapeseed oil $(5$ or $10 \%$ of DM) or tallow (10\% of DM), the PL contents were not altered significantly but the FFA contents increased by 91,145 and $107 \%$ for the SAB and 73,85 and $140 \%$ for the LAB $(P<0.05)$. The increase in FFA content was associated with the occurrence of cytoplasmic lipid droplets in both bacteria.

Dans le rumen de la vache laitière recevant des régimes riches en lipides non protégés, la quantité des bactéries adhérant à la phase solide (BAS) et de bactéries associées à la phase liquide (BAL) reste inchangée, mais leur contenu en acides gras totaux augmente de 54 à $96 \%$ (Bauchart et al., 1986). Aussi était-il intéressant d'étudier les modifications du métabolisme lipidique bactérien avec ce type de régimes par le biais de la composition et de la teneur des différentes classes de lipides dans les 2 populations bactériennes.

Matériel et méthodes. Quatre vaches FFPN, munies de canule du rumen, ont reçu en carré latin 4 rations constituées d'un mélange de foin de fétuque et d'aliment concentré $(50 / 50)$ : une ration témoin $(\mathrm{T})$, et 3 rations contenant, par rapport à la matière sèche, soit $5 \%$ (C5) ou $10 \%$ (C10) d'huile de colza, soit $10 \%$ de suif $(\mathrm{S} 10)$. Les échantillons bactériens ont été préparés à partir d'un mélange de 4 prélèvements de contenus de rumen effectués $1 / 2 \mathrm{~h}$ avant et 2,4 et $6 \mathrm{~h}$ après la prise du repas du matin, selon une méthode décrite par Bauchart et al. (1986).

Les lipides bactériens ont été extraits successivement par le mélange chloroforme/méthanol $2 / 1(\mathrm{~V} / \mathrm{V})$ puis par I'hexane-HCl. La quantité totale de lipides (y compris les pigments lipophiles) a été déterminée par gravimétrie. La composition et la teneur des différentes classes de lipides ont été mesurées par chromatographie sur couche mince et détection par ionisation de flamme (CCM-DIF) avec l'analyseur latroscan en présence d'un étalon interne (méthyl C16:0). La teneur en acides gras totaux (AGT) a été déterminée à la fois par CCM-DIF et par chromatographie en phase gazeuse.

Résultats et discussion. Pour tous les régimes étudiés, les bactéries fixées (BAS) présentent des teneurs en AGT et en lipides totaux 2 fois supérieures $(\mathrm{P}<0,05)$ à celles des bactéries libres (BAL) (fig. 1). La distribution des lipides se caractérise pour les BAS par la prépondérance des acides gras libres (AGL) et pour les BAL par celle des phospholipides (PL) (+ glycolipides) (fig. 1). L'addition de lipides à la ration ne modifie pas la teneur en $\mathrm{PL}$ des 2 populations mais aug- 

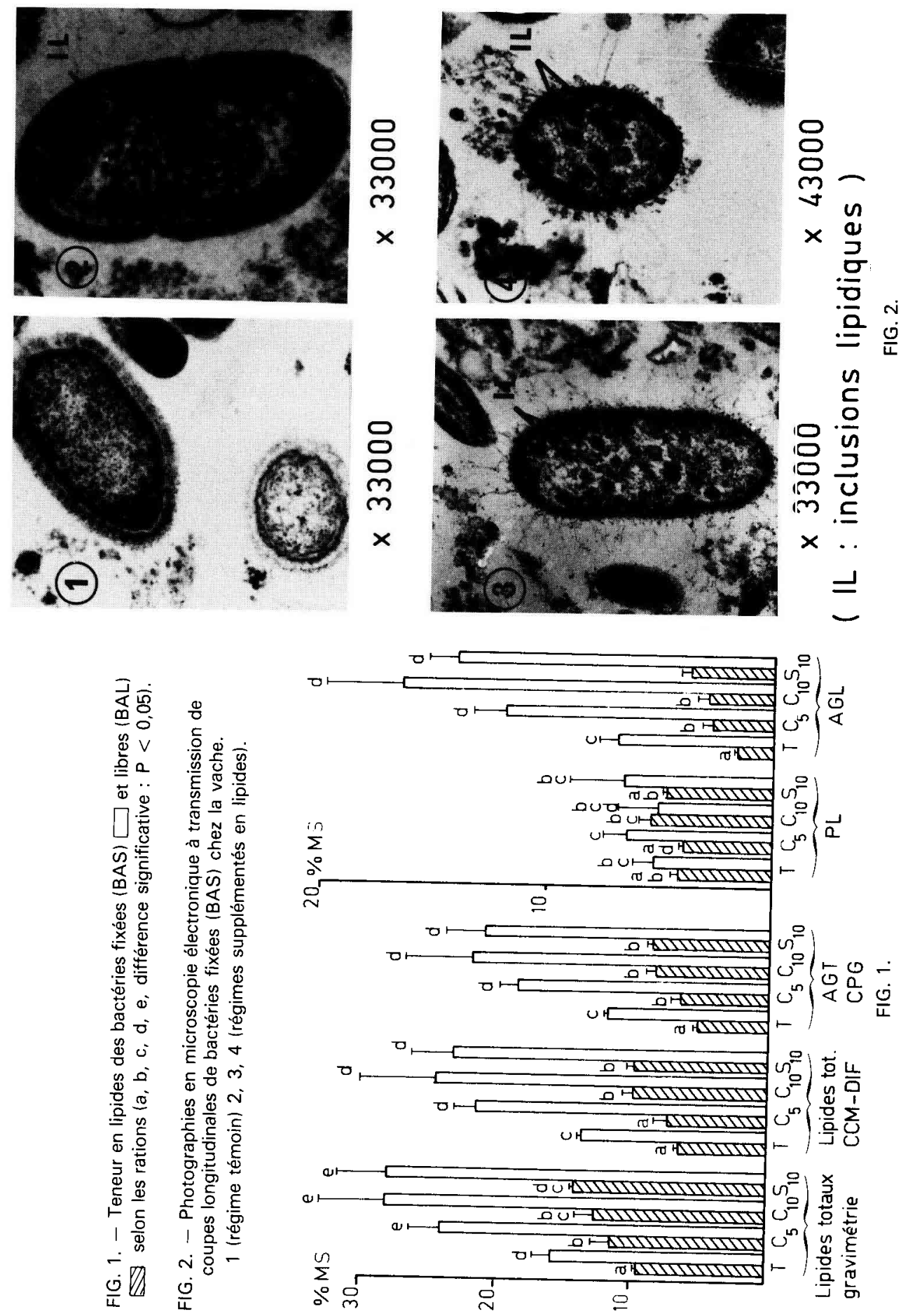
mente la teneur en AGL (P<0,05) de 91, 145 et $107 \%$ pour les BAS et de 73 , 85 et $140 \%$ pour les $B A L$ dans le cas des régimes $C 5, C 10$ et $S 10$ respectivement. Les diglycérides $(0,4$ à $1,6 \%)$, le cholestérol libre $(0,2$ à $1,1 \%)$ et estérifié $(0,1$ à $0,6 \%)$ sont des composés très minoritaires, comme les triglycérides qui n'apparaissent, à l'état de trace, que pour les régimes $C 10$ et $S 10(0,2$ à $0,5 \%)$. Contrairement aux PL, la composition de la fraction AGL des 2 populations bactériennes est fortement modifiée par la nature et la quantité d'acides gras ingérés.

Les observations en microscopie électronique à transmission (MET) montrent que les AGL s'accumuleraient uniquement à l'intérieur de la bactérie sous forme de multiples inclusions; sans dépôt sur la membrane externe (fig. 2). Czerkawski (1976) ayant observé avec des régimes usuels une baisse des teneurs en AGL des bactéries libres après la prise du repas, des études en cinétique au cours de la journée nous permettront de préciser la période et l'intensité de mobilisation de la fraction AGL des 2 populations bactériennes.

Bauchart D., Legay-Carmier F., Doreau M., Jouany J.-P., $1986 . \quad$ Reprod. Nutr. Dévelop., 26, 51-52. Czerkawski J. W., 1976. J. Sci. Food Agric., 27, 621-632.

Merry R. J., Mc Allan A. B., 1983. Br. J. Nutr., 50, 701-709. 